\title{
Research experiment on infiltration and runoff in Jujube land of northern Shaanxi Province
}

\author{
XIAOYU SONG ${ }^{1} \&$ PENG BAI ${ }^{2}$ \\ 1 State Key Laboratory Base of Eco-hydraulic engineering in Arid Area, Xi'an University of Technology, Xi'an, Shaanxi \\ Province 710048, China \\ songxy@xaut.edu.cn \\ 2 Key Laboratory of Water Cycle \& Surface Process, Institute of Geographic Sciences and Natural Resources Research, \\ CAS, Beijing 100101, China \\ 287167854@qq.com
}

\begin{abstract}
To provide guidance for the efficient use of rainwater in Jujube forests of the northern Shaanxi Province, research on the processes of infiltration and runoff under field simulated rainfall were conducted. The process of infiltration and runoff-yield on sloping land was simulated with Richards equation and the water balance equation under different rainfall intensities and soil water content, in the north of Shaanxi province. It reached results via comparing with observation results: the mean relative error of the period cumulative infiltration was less than $3 \%$, with a root mean squared error (RSME) less than 0.3 . The mean relative error of the period cumulative runoff was less than $12.5 \%$, RSME $<0.4$. The simulation results were reasonable; however, the simulation ponding time generally lagged behind measured ponding time probably because of spatial variation of saturated hydraulic conductivity and uneven rainfall.
\end{abstract}

Key words Richards's equation; infiltration simulation; finite difference method; simulated rainfall; ponding time

\section{INTRODUCTION}

The rainfall infiltration process is an important component of the soil water cycle, and also is the basis of agricultural irrigation, engineering design and hydrological process simulation. Scholars at home and abroad have carried out a lot of research on soil water infiltration processes, and established a series of models of the physical foundation and empirical formula. After the GreenAmpt infiltration model in 1911, there appeared successively Richards equation, the Horton model, Philip model, Smith model, etc. Most domestic scholars study the improvement and application of foreign classic infiltration models. Experience with the infiltration equation shows the physical model has clear physical meaning, and it is easy to establish its characteristic parameters and the relationship between soil physical characteristics, and has been widely used. In physical models, whether the Green-Ampt model based on Darcy's law is simplified or Philips model based on soil water movement equation analytical of method, or the Parlange model, is only applicable to simple soil moisture movement under the definite condition; for complex conditions of soil moisture movement problem, numerical solution methods are still the most objective and effective method.

At present, Richards equation is widely applied in foreign hydrology, agriculture, engineering and construction simulation software, such as: HYDRUS, SWAP, the SWMS-2D, etc. Domestic researchers have not given enough attention to Richards's infiltration equation and have mostly focused on indoor soil column infiltration processes or point source drip irrigation simulation application, research that is less applicable to the condition of field rainfall. In this paper, on the basis of an artificial rainfall experiment in the slope land of northern Shaanxi province, the finite difference method is used for solving Richards equation numerical simulation, and we analysed its application to the process of rainfall infiltration and runoff. This could provide a reference for the equation's application in prediction of soil moisture, runoff and slope surface erosion.

\section{RESEARCH AREA AND EXPERIMENT DESIGN}

The field rain experiment was carried out March 2010-September 2011 in the Jujube demonstration garden of Yulin city, Shaanxi Province. Data testing and analysis were completed in December 2012. MiZhi county is in northern Shaanxi; Yulin Middle East, on the middle reaches of Wuding River, is located between longitudes $109^{\circ} 49^{\prime} \mathrm{E}$ and $109^{\circ} 29^{\prime} \mathrm{E}$, and latitudes $38^{\circ} 39^{\prime} \mathrm{N}$ and 
$37^{\circ} 5^{\prime} \mathrm{N}$. There is a total population of 216000 , among them, the agricultural population accounts for $89.4 \%$; the total land area is $1212 \mathrm{~km}^{2}$. Corn is the main crop on the plain; fruit trees and grain crops are planted mainly on sloping land. Under the state policy measures of returning farmland to forest, local farmers have planted large areas of fruit trees on slope land; the most widely planted area is of the Jujube tree. Mizhi county belongs to the typical loess plateau hilly-gully region, the semi-arid climate zone of Wuding River watershed, and the topography overall is high in the middle and low in the east and west. There is lack of rain throughout the year; the temperature difference between day and night is big. Average rainfall is $413 \mathrm{~mm}$, mainly concentrated in 7-9 months; the biggest annual rainfall is $691 \mathrm{~mm}$ and the minimum is $268.3 \mathrm{~mm}$. Yellow spongy soils are the main regional soil; soils are soft, and soil erosion is serious. Varieties of Jujube are planted in the experimental area; after about 7-8 years, the plant height is $2 \mathrm{~m}$ or so; the plant row spacing is $2 \mathrm{~m} \times 3 \mathrm{~m}$; the new dwarf density cultivation mode has been adopted.

The rainfall runoff experiment was conducted in runoff plots. Runoff plot were chosen on flat land, and where the terrain, slope direction, soil and vegetation were representative of the area, and where we could get rid of the weeds, and the slope land and slope direction were uniform, and there was a water source for the artificial rainfall close by. According to the purpose of soil water transformation test with rainfall on slope, 10 runoff plots were built. The slopes were oriented facing the sun. The width of the runoff plots is $3 \mathrm{~m}$, and they are bounded with asbestos shingle lateral seepage prevention treatment, $30-40 \mathrm{~cm}$ deep. The outlets were built in a V shape, and runoff was collected by the runoff bucket. The source of water supply reservoir is located at the top of the mountain; water was led through pipes to the runoff plots. The vertical height between the top of the mountain reservoir and runoff plots was about $40 \mathrm{~m}$; the artificial rainfall was driven by the gravity head difference. Rain showers were created using an 1804 scattering-type nozzle (Fish Bird brand, USA), and the jet radius was $4 \mathrm{~m}$. The single measure of the spray nozzle was $0.8 \mathrm{~m}^{3} / \mathrm{h}$; the rain intensity can be adjusted by adjusting the valve opening and nozzle direction; rainfall evenness was more than 0.8 .

Rainfall runoff experiments were carried under the condition of no wind. Rain cylinders were set evenly setting to measure rainfall intensity. The start time of runoff yield was recorded after the rain began; the rainfall duration was 30 minutes. After runoff began, the runoff volume was read and water and sand samples taken in a cylinder every 2 minutes. Water and sediment samples were set in indoors for $24 \mathrm{~h}$, and then the supernatant, filtered off to determine sediment concentration after drying at $105^{\circ} \mathrm{C}$ in an oven for 8 hours.

Initial soil water content was determined by the drying method, and soil bulk density was measured by cutting rings every $10 \mathrm{~cm}$ depth. Due to the short slope length, regardless of the process of flow, the infiltration amount was got through the difference between the rainfall and runoff, i.e. according to the principle of water balance.

The soil water characteristic curve was tested by centrifuge; analyses of soil particles were made by sieve analysis method and the pipette method of determination. Saturated hydraulic conductivity was measured in the field with a $13 \mathrm{~cm}$ diameter undisturbed field soil column in plexiglass; the sampling depth was about $30 \mathrm{~cm}$, and the bottom of the soil column enclosed with gauze; a Markov bottle provided the water head. After waiting for bottom water flow, we determined the flow of water every 10 min until a constant flow of water occurred; there were then three repeats.

\section{RAINFALL INFILTRATION AND RUNOFF YIELD MODEL}

\subsection{Richards equation}

Richards equation based on the fluid continuity equation and Darcy's law, describes unsaturated soil water movement, with vertical infiltration:

$$
\frac{\partial \theta}{\partial t}=\frac{\partial}{\partial z}\left[K(\theta)\left(\frac{\partial \theta}{\partial z}+1\right)\right]
$$


where, $\theta$ is soil volumetric water content, $\mathrm{cm}^{3} / \mathrm{cm}^{3}$, and $t$ is time, min, and $z$ is coordinates in vertical direction for (positive upward), $K$ is the unsaturated hydraulic conductivity, $\mathrm{cm} / \mathrm{min}$.

The initial conditions for the rainfall infiltration process are as follows:

$$
\theta(z, 0)=\theta(z)
$$

The upper boundary conditions: rainfall infiltration in the early, the surface water infiltration capacity is greater than the precipitation intensity and infiltration rate is equal to the rainfall intensity, is the second boundary condition:

$$
-\left.D(\theta) \frac{\partial \theta}{\partial z}\right|_{z=0}+K(\theta)=f(t)
$$

where $D$ is the soil moisture diffusivity, $D=K \mathrm{~d} \psi / \mathrm{d} \theta$ and $\psi$ is the soil matric potential, $\mathrm{cm}, f$ is the soil infiltration rate. When surface soils are saturated, and the infiltration rate is less than the rainfall intensity, the stagnant water appears at the surface, and the upper boundary condition is transformed into the first kind of boundary condition:

$$
\theta(0, t)=\theta_{0}(t) \psi(0, t)=\psi_{0}(t)
$$

where $\theta_{0}(t)$ and $\psi_{0}(t)$ are the value of water content and matric potential respectively.

The lower boundary conditions: slope in the loess plateau, underground water level is deep, the lower boundary conditions is the gravity drainage boundary, the corresponding moisture flux is the hydraulic conductivity in the bottom boundary, at this point, the moisture content or matric potential gradient in the border is zero, namely:

$$
\left.\frac{\partial \theta}{\partial z}\right|_{z=L}=\left.0 \quad \frac{\partial \psi}{\partial z}\right|_{z=L}=0
$$

where $L$ is lower boundary depth, $\mathrm{cm}$.

Production of flow simulation can be obtained as the difference between precipitation $(P)$ and the cumulative infiltration amount $(I)$ through the water balance equation:

$$
R=P-I
$$

Unsaturated hydraulic conductivity $K$ is generally calculated through the soil water characteristic curve, currently the most widely used for soil water characteristic curve is the Van Genuchten expression:

$$
\theta(h)= \begin{cases}\theta_{r}+\frac{\theta_{s}-\theta_{r}}{\sqrt{1+\left.|\partial h|^{n}\right|^{n}}} & h<0 \\ \theta_{s} & h \geq 0\end{cases}
$$

where $h$ is the suction of the soil, $\mathrm{cm}, \theta_{s}$ is soil saturated water content, $\theta_{r}$ is water content for soil retention and $m$ is the shape factor, $m=1-1 / n$.

Mualem (1976) proposed the model according to the calculation of soil water characteristic curve of unsaturated soil hydraulic conductivity, unsaturated hydraulic conductivity of soil can be represented as:

$$
K(h)=K_{s} S_{e}^{l}\left[1-\left(1-S_{e}^{1 / m}\right)^{m}\right]^{2}
$$

where $S_{e}$ is effective saturation, the expression is:

$$
S_{e}=\frac{\theta-\theta_{r}}{\theta_{s}-\theta_{r}}
$$

\subsection{Model solution}

The model is solved by the finite difference method, according to the expression of the soil water movement parameter, initial conditions and boundary conditions, discrete according to certain time and space. Forecasting the soil moisture content at the end of time by the initial soil moisture content, got soil moisture content at the end of the period using the catch-up method for solving differential equations, and forecasts and calculated values of soil moisture that met the 
requirements of error, were considered in that iterative process, then solving the next stage, otherwise, the calculation is based on the soil moisture content of the session at the end of the value for the new forecast, continue to iteration, until meet the error requirement.

\section{RESULTS AND ANALYSIS}

\subsection{Rainfall infiltration and runoff simulation under different rainfall intensity}

The experiment was conducted in Jujube runoff plots. Due to the little rainfall in early May of the experimental area, the Jujube was just sprouting (ignoring the influence of the rainfall intercepted), three runoff plots, which had the same initial moisture content, were selected to conduct the infiltration and runoff yield test under different rainfall intensity. The rainfall duration was $30 \mathrm{~min}$; rainfall, infiltration and runoff yield are shown in Table 1.

Table 1 Rainfall infiltration, and runoff cases in runoff plots under different intensity.

\begin{tabular}{llllrr}
\hline $\begin{array}{l}\text { Experiment } \\
\text { number }\end{array}$ & $\begin{array}{l}\text { Rainfall intensity } \\
(\mathrm{mm} / \mathrm{min})\end{array}$ & $\begin{array}{l}\text { Rainfall } \\
\text { evenness }\end{array}$ & $\begin{array}{l}\text { Initial soil moisture } \\
\text { content }\left(\mathrm{cm}^{3} / \mathrm{cm}^{3}\right)\end{array}$ & $\begin{array}{l}\text { Runoff yield } \\
\text { time }(\mathrm{min})\end{array}$ & $\begin{array}{l}\text { Total runoff } \\
(\mathrm{mm})\end{array}$ \\
\hline 1 & 0.8 & 0.91 & & 18.86 & 1.78 \\
2 & 1.3 & 0.80 & 0.08 & 9.17 & 10.77 \\
3 & 1.0 & 0.85 & & 12.95 & 3.22 \\
\hline
\end{tabular}

With the above rainfall infiltration, the runoff model for different rainfall intensities during the test to simulate runoff, $\mathrm{R}_{1}, \mathrm{R}_{2}, \mathrm{R}_{3}$ represented the cumulative infiltration and runoff measured values for which rainfall intensity was $1.3,1.0,0.8 \mathrm{~mm} / \mathrm{min}$ respectively; $\mathrm{M}_{1}, \mathrm{M}_{2}$ and $\mathrm{M}_{3}$ represented their simulated values, respectively. The observed and simulated values of cumulative infiltration and runoff under different rainfall intensities are shown in Fig. 1.
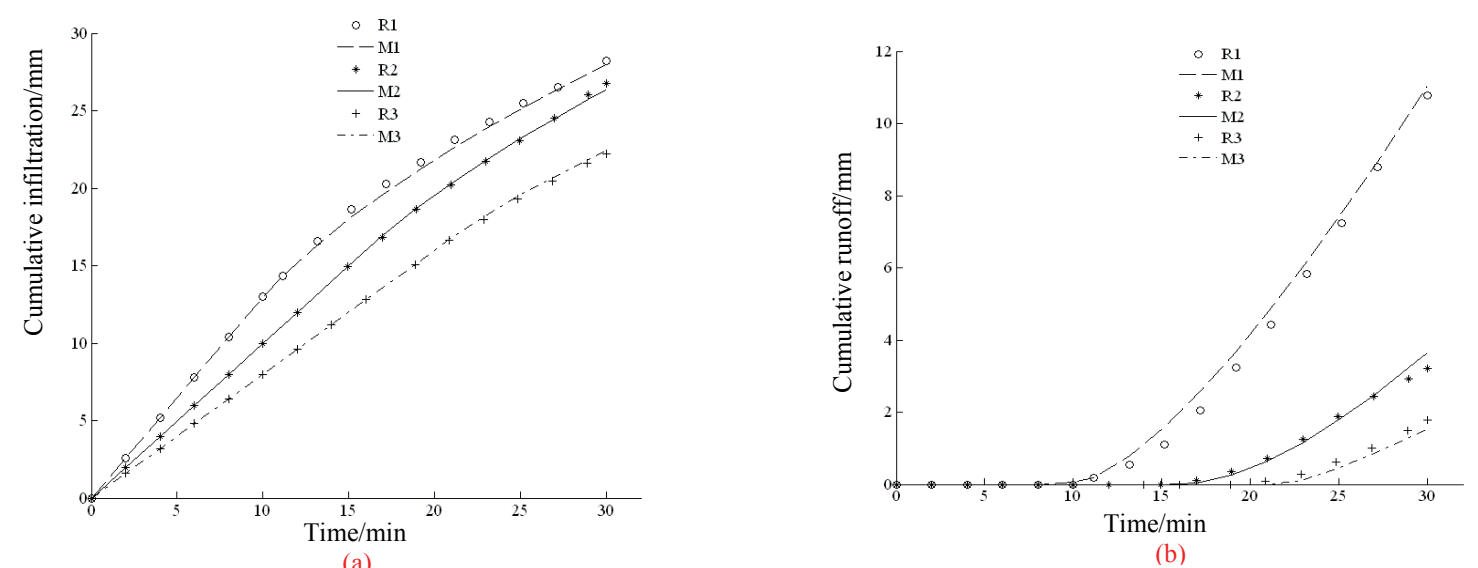

Fig. 1 The measured and simulated cumulative infiltration (a), and (b) cumulative runoff, under different rainfall intensity in runoff plots.

The influence of rainfall intensity on soil water infiltration is mainly reflected in the size of the rainfall intensity and soil infiltration ability; in the course of rainfall, soil water infiltration capacity decreases with the increase of soil moisture content. In the initial rainfall stage, rainfall intensity is less than soil water infiltration capacity, the actual soil infiltration rate is equal to water supply intensity, and all rainfall is infiltrated. With the decrease of the soil water infiltration capacity, a moment later, the rainfall intensity is less than soil water infiltration capacity, the groundwater flow began. Figure 1 shows that under the same conditions, the greater the rainfall intensity and faster runoff time, the shorter is the interval of reaching stability state of infiltration, and the cumulative infiltration amount and runoff are the greater. The rainfall duration is $30 \mathrm{~min}$, the accumulation of $R_{1}$ is 3.34 times that of $R_{2}, 6.06$ times that of $R_{3}$. Figures 1 (a) and $1(b)$ show that rainfall infiltration and runoff simulation results by this rainfall infiltration-runoff model for 
different rainfall intensities, agree well with the measured values, which is more in line with actual soil infiltration, runoff rule.

\subsection{Different initial soil moisture content of rainfall infiltration, runoff simulation}

To test the simulation effect of rainfall infiltration and runoff by models with different initial moisture content conditions, within the tests on Jujube runoff plots in early May, the selection of different initial moisture content of three runoff plots with the same rainfall intensity of artificial rainfall infiltration and runoff yield test, 30 min rainfall. Rainfall infiltration and runoff yields overall are shown in Table 2.

Table 2 Rainfall infiltration, runoff cases in runoff plots under initial soil moisture content.

\begin{tabular}{llllll}
\hline $\begin{array}{l}\text { Experiment } \\
\text { number }\end{array}$ & $\begin{array}{l}\text { Rainfall } \\
\text { intensity } \\
(\mathrm{mm} / \mathrm{min})\end{array}$ & $\begin{array}{l}\text { Rainfall } \\
\text { evenness }\end{array}$ & $\begin{array}{l}\text { Initial soil moisture } \\
\text { content }\left(\mathrm{cm}^{3} / \mathrm{cm}^{3}\right)\end{array}$ & $\begin{array}{l}\text { Runoff yield time } \\
(\mathrm{min})\end{array}$ & $\begin{array}{l}\text { Total runoff } \\
(\mathrm{mm})\end{array}$ \\
\hline 3 & 1.0 & 0.85 & 0.08 & 12.95 & 3.22 \\
4 & & 0.82 & 0.15 & 9.50 & 6.56 \\
5 & 0.88 & 0.24 & 6.78 & 10.80 \\
\hline
\end{tabular}

Continuing to use the rainfall infiltration and runoff yield model to simulate the process of different soil moisture content of the experiment, $T_{1}, T_{2}$ and $T_{3}$ represented the cumulative infiltration and runoff measured values when initial soil moisture content was $0.08,0.15,0.24$ respectively; $\mathrm{M}_{1}, \mathrm{M}_{2}, \mathrm{M}_{3}$ represented their simulated values respective. The observed and simulated values of cumulative infiltration and runoff under different initial soil water content are shown in Fig. 2.

It can be seen from Fig. 2 that soil initial moisture content has an important influence on the rainfall infiltration and runoff process. The greater the initial soil moisture, the faster runoff times, and the smaller the average infiltration rate, the shorter the stable infiltration phase time. At the same time, the greater the cumulative runoff based on the measured values, cumulative runoff of $\mathrm{T}_{3}$ is 1.65 times that of $\mathrm{T}_{2}, 3.35$ times that of $\mathrm{T}_{1}$.

Figure 2 shows that rainfall infiltration and runoff simulation results by this rainfall infiltration, runoff model for different initial soil moisture content, agree well with the measured values, which are more in line with the actual soil infiltration, runoff rule.

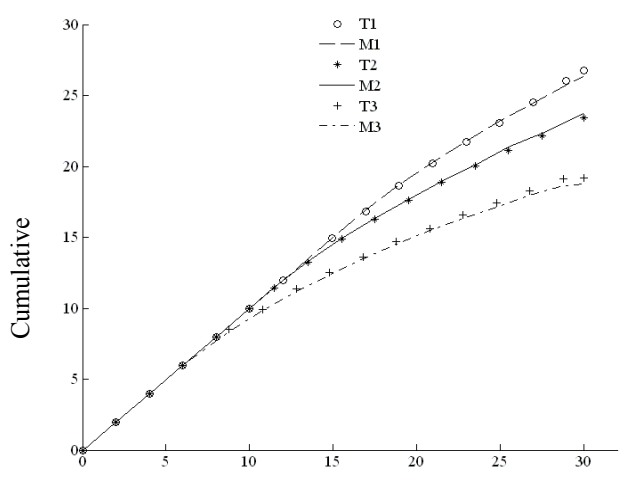

Time/min (a)

Fig. 2 The measured and simulated cumulative infiltration different initial soil moisture content in runoff plots.

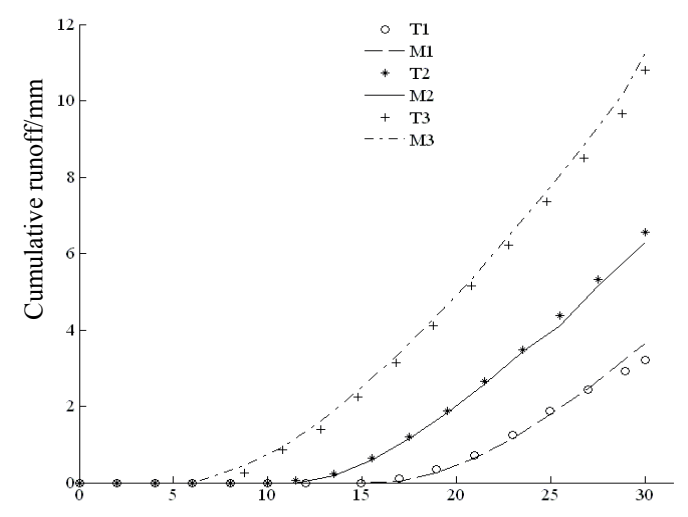

(a) Time/min (b) (a) and cumulative runoff (b), under the

\subsection{Error analysis}

Figures 1 and 2 show the rainfall infiltration and runoff yield results of numerical simulation in runoff plots by the rainfall runoff yield model are consistent with the actually measured values, which is more in accordance with the practice of soil infiltration, runoff regulation. To quantitat- 
ively analyse the simulation accuracy of the model, the error analysis of the simulated values and measured values for the different times, and the calculation results are shown in Table 3 .

Table 3 Statistical analysis on simulated and measured values of rainfall infiltration and runoff.

\begin{tabular}{|c|c|c|c|c|c|c|}
\hline \multirow[t]{2}{*}{$\begin{array}{l}\text { Experimental } \\
\text { number }\end{array}$} & \multicolumn{2}{|c|}{$\begin{array}{l}\text { Start time of runoff yield } \\
\text { (min) }\end{array}$} & \multicolumn{2}{|c|}{ Total runoff $(\mathrm{mm})$} & \multicolumn{2}{|c|}{ Total infiltration (mm) } \\
\hline & $\begin{array}{l}\text { Measured } \\
\text { value }\end{array}$ & $\begin{array}{l}\text { Simulated } \\
\text { value }\end{array}$ & $\begin{array}{l}\text { Relative } \\
\text { error }(\%)\end{array}$ & $\begin{array}{l}\text { Square root } \\
\text { error }\end{array}$ & $\begin{array}{l}\text { Relative } \\
\text { error }(\%)\end{array}$ & $\begin{array}{l}\text { Square root } \\
\text { error }\end{array}$ \\
\hline 1 & 18.86 & 20.89 & 12.5 & 0.19 & 2.1 & 0.11 \\
\hline 2 & 9.17 & 9.97 & 9.2 & 0.36 & 1.4 & 0.29 \\
\hline 3 & 12.95 & 15.50 & 7.9 & 0.17 & 0.6 & 0.15 \\
\hline 4 & 9.50 & 11.64 & 4.5 & 0.13 & 0.6 & 0.11 \\
\hline 5 & 6.78 & 7.71 & 6.0 & 0.25 & 1.6 & 0.24 \\
\hline
\end{tabular}

Table 3 shows that cumulative runoff simulation in addition to the test \#1's relative error is $12.5 \%$, the relative error is within $10 \%$, and square root error $<0.4$; cumulative infiltration volume of the relative error is $<3 \%$, square root error is less than 0.3 , simulation results are satisfactory.

It also can be seen from Table 3 that the simulation value of runoff start time is greater than the measured values generally; this is because the slope of saturated hydraulic conductivity caused by spatial variability and the inhomogeneity of rainfall. Due to the complexity of the vadose zone structure, soil bulk density and large pore space differences can cause different saturated hydraulic conductivity, which can lead to local runoff yield in advance. In addition, because of the heterogeneity of rainfall, rainfall intensity in the relatively large surface area first began runoff, also contributed to simulate runoff start time lag causes.

\section{CONCLUSIONS}

In this paper, Richards infiltration equations combined with the water balance equation simulated the rainfall infiltration and runoff process in runoff plots on a loess slope under different rainfall intensities and different initial moisture conditions. Comparing with the measured values, the simulation results show that the model is reasonable, and can be used as the area rainfall infiltration and runoff yield calculation formula. The simulated runoff start time generally lags behind the actual start time value, because the slope saturated hydraulic conductivity and the spatial variability of rainfall inhomogeneity. The impact of runoff starting time needs to be further studied in order to better guide local Jujube moisture and runoff forecasting.

Acknowledgements This work was financially supported by the National Natural Science Foundation of China (grant number 51239009, 41171034) and Shaanxi provincial natural science foundation of China (key) project(grant number 2013JZ012, 14JS059, 2013JC18). The reviewing editor and reviewers are gratefully thanked for their constructive comments.

\section{REFERENCES}

Guo, X.H., Sun, X.H. and Ma, J.J. (2009) Numerical simulation for root zone soil moisture movement of apple orchard under rainfall-irrigation-evaporation. Transactions of the Chinese Society for Agricultural Machinery 40(7), 68-73.

Jacquesa, D. et al. (2008) Modelling coupled water flow, solute transport and geochemical reactions affecting heavy metal migration in a podzol soil. Geoderma 145(3-4), 449-461.

Kroes, J.G, et al. (1997) SWAP version 3.2 Theory description and user manual. Wageningen: Department Water Resources, Wageningen Agricultural University, Technical Document 45.

Li, Y., et al. (2007) Green-Ampt model and its application. Journal of Northwest A\&F University: Natural Science Edition $35(2), 225-230$.

Li, Y., et al. (2007) Mathematical simulation of soil water movement under infiltration, redistribution and evaporation. Journal of Irrigation and Drainage 26(1), 5-8.

Liang, H.J., et al. (2008) Numerical simulation of soil water movement under infiltration irrigation. Transactions of the Chinese society of Agricultural Engineering 24(10), 64-68. 